\title{
Intestinal Uptake of Retinol in Suckling Rats: Characteristics and Ontogeny
}

\author{
HAMID M. SAID, DAVID ONG, AND REYADH REDHA \\ Department of Pediatrics [H.M.S., R.R.], Molecular Physiology/Biophysics [H.M.S., R.R.], and Biochemistry \\ [D.O.], Vanderbilt University School of Medicine, Nashville, Tennessee 37232
}

\begin{abstract}
Uptake of rotinol in the developing intestine of suckling rats (14-15 day old) and its maturation in adult rats (90 day old) was examined using intestinal everted sacs. Uptake of retinol $(0.06 \mu \mathrm{M})$ in the jejunum of suckling and adult rats was linear for $5 \mathrm{~min}$ incubation and occurred at a rate of 31.20 and $6.98 \mathrm{pmol} / \mathrm{g}$ tissue $/ \mathrm{min}$, respectively. In both age groups, uptake of retinol $(0.06$ $\mu \mathrm{M})$ was significantly higher $(p<0.01)$ in the jejunum than the ileum. Uptake of retinol was significantly higher $(p<0.01)$ in suckling rats as compared to adult rats both in the jejunum and the ileum. In both suckling and adult rats, the uptake of retinol in the jejunum was 1 ) saturable with a $V_{\max }$ value of 19.78 and $6.24 \mathrm{nmol} / \mathrm{g}$ tissue $/ 5 \mathrm{~min}$ and an apparent $K_{m}$ value of 16.20 and $8.19 \mu \mathrm{M}$, respectively, 2) not affected by metabolic inhibitors, and 3) partially temperature dependent $\left(Q_{10}=2.51\right.$ and 1.92 , respectively). The structural analogues retinal $(50 \mu \mathrm{M})$ and retinoic acid $(50 \mu \mathrm{M})$ did not affect the uptake of $\left[{ }^{3} \mathrm{H}\right]$ retinol $(0.06 \mu \mathrm{M})$ whereas unlabeled retinol $(50 \mu \mathrm{M})$ caused significant $(p<0.01)$ inhibition. No difference in retinol metabolism by intestinal tissue was observed in the two age groups. These results demonstrate that retinol uptake in suckling rats is similar to that of adult rats in being a passive carrier-mediated process. The results also suggest that a decrease in the number and/or activity and an increase in the affinity of the uptake system of retinol occurs with maturation. (Pediatr Res 24: 481-485, 1988)
\end{abstract}

\section{Abbreviations}

HPLC, high-performance liquid chromatography PEG, polyethylene glycol

CRBP II, cellular retinol binding protein II

Vitamin A is an important lipid-soluble micronutrient that is required for normal growth, development, differentiation of epithelial cells, and preservation of vision. Vitamin A cannot be synthesized in the body, and, therefore, must be obtained from the diet by intestinal absorption. Uptake (and transport) of vitamin $\mathrm{A}$ in the developed intestine of adult animals has been examined previously $(1,2)$ but no study is available describing the mechanism and site of maximum uptake of the vitamin in the developing intestine of suckling animals and its subsequent maturation (ontogeny) in adulthood. The structure and function of the gastrointestinal tract is known to undergo ontogeny during the early stages of life (3). This includes changes in the mecha-

Received March 15, 1988; accepted June 14, 1988.

Correspondence and reprint requests Dr. Hamid M. Said, Division of Gastroenterology, Department of Medicine, University of California School of Medicine, Irvine, CA 92717

Supported by NIH Grant NIDDKD AM 26657, DK 32642, and DK 39501. nism, capacity, and site of maximum transport of nutrients and substrates (4-10). These changes, however, do not follow a unified pattern. In this study we examined the intestinal uptake and metabolism of vitamin A alcohol (retinol) in suckling rats and determined its ontogeny by comparing the results to that of adult rats. We used a well-validated intestinal technique in our studies.

\section{MATERIALS AND METHODS}

The following materials were obtained commercially: [15$\left.{ }^{3} \mathrm{H}(\mathrm{N})\right]$ retinol (sp. act. $18.8 \mathrm{Ci} / \mathrm{mmol}$ ) and $\left[1,2-{ }^{14} \mathrm{C}\right] \mathrm{PEG}$ (PEG4000) from New England Nuclear, Boston, MA; unlabeled retinol, retinal, retinoic acid, and taurocholate from Sigma Chemical Company, St. Louis, MO; scintillation cocktail (ASC) from Amersham/Searle, Des Plaines, IL. All other chemicals and reagents were obtained commercially and were of analytic quality. The radiochemical purity of $\left[{ }^{3} \mathrm{H}\right]$ retinol was determined by HPLC (11) and ranged from 98 to $92 \%$ over the course of the experiments. A single minor impurity was present but was not taken up by intestinal tissue and consequently had no effect on the results.

Suckling and adult (male) Sprague-Dawley rats were purchased from Sasco, Omaha, NE. Mothers and adult rats were fed Purina Rat Chow (St. Louis, MO) and tap water ad libitum. The National Council's guidelines for the care and use of laboratory animals were followed. Uptake studies were performed in suckling ( 15 day old) and adult ( 90 day old) rats by the use of the everted sac technique (12). We chose this technique because of its simplicity, reproducibility, and the fact that in this preparation, uptake processes can be examined under extreme conditions (e.g. effect of metabolic inhibitors and temperature). Brush border membrane vesicles cannot be used to study retinol transport because of the lipid nature of the compound and the need for bile salt(s) to disperse the vitamin in aqueous incubation media that destroys vesicles. Rats were killed by an overdose of ether. The abdomen was opened and $20 \mathrm{~cm}$ of the jejunum (starting 8 and $14 \mathrm{~cm}$ from the pylorus of suckling and adult rats, respectively) and the ileum (the most distal $20 \mathrm{~cm}$ of the small intestine) were removed and washed with ice-cold buffer. Everted sacs (4 cm in length) were then prepared as previously described $(6,7)$. The incubation medium was a micellar solution prepared in Krebs-Ringer phosphate buffer $\left(20 \mathrm{mM} \mathrm{NaH}_{2} \mathrm{PO}_{4}\right.$, $125 \mathrm{mM} \mathrm{NaCl}, 4.93 \mathrm{mM} \mathrm{KCl}, 1.23 \mathrm{mM} \mathrm{MgSO}_{4}, 0.85 \mathrm{mM}$ $\mathrm{CaCl}_{2}$, and $10 \mathrm{mM}$ glucose, $\mathrm{pH} 6.5$ ) with $10 \mathrm{mM}$ taurocholate and the desired concentration of retinol. The incubation medium was prepared (in the dark) by adding aliquots of stock $\left[{ }^{3} \mathrm{H}\right]$ retinol and unlabeled retinol (in ethanol) to $1 \mathrm{ml}$ of Krebs-Ringer phosphate buffer containing $10 \mathrm{mM}$ taurocholate. The solution was vortexed for $30 \mathrm{~s}$ then brought to the desired volume (usually $100 \mathrm{ml}$ ) by gradually adding taurocholate containing buffer under continuous stirring. The solution was then left to stir for an additional $30 \mathrm{~min}$. A trace amount of $\left[{ }^{14} \mathrm{C}\right] \mathrm{PEG}-4000$ was 
added to the incubation medium as a nonabsorbable marker. The serosal compartment was filled with Krebs-Ringer phosphate buffer. Incubation was carried out in $10 \mathrm{ml}$ Erlenmeyer flasks containing $5 \mathrm{ml}$ of continuously-oxygenated $\left(100 \% \mathrm{O}_{2}\right)$ incubation medium at $37^{\circ} \mathrm{C}$ (unless otherwise stated) in a shaking water bath ( 80 oscillation/min) (shaking and bubbling of the incubation medium decrease the effect of the unstirred water layer on the uptake process) (13). At the end of incubation sacs were removed, washed, and the serosal medium was separated from the tissue. Tissue was weighed and then digested as described previously $(8)$ and the tissue and serosal $\left[{ }^{3} \mathrm{H}\right]$ and $\left[{ }^{14} \mathrm{C}\right]$ radioactivity was determined by dual counting and calculation technique (14). Uptake of the substrate was corrected for nonspecific binding (and for adherent incubation fluid remaining on the sac wall), then calculated as described (8). In this study, we found the serosal appearance of $\left[{ }^{3} \mathrm{H}\right]$ subtrate(s) to be minimal and ranged between 1 and $3 \%$ of the total uptake of the substrate by the everted sacs and always paralleled tissue uptake. Thus, our presented data represents uptake into the tissue compartment (approximately 97 to $99 \%$ ).

Metabolism of retinol by intestinal tissue of suckling and adult rats was determined by HPLC as described previously $(11,15)$. Four jejunal sacs from suckling and adult rats were incubated for $5 \mathrm{~min}$ in the presence of $0.06 \mu \mathrm{M}\left[{ }^{3} \mathrm{H}\right]$ retinol. At the end of incubation, tissue and serosal samples were pooled separately. Intestinal tissue and serosal samples were extracted with chloroform/methanol and the extracted radioactivity was subjected to HPLC.

The viability of the in vitro tissue preparation has been previously demonstrated by measuring transmural potential difference and $\mathrm{L}-\left[{ }^{3} \mathrm{H}\right]$ leucine $(20 \mu \mathrm{M})$ and $5-\left[{ }^{14} \mathrm{C}\right]$ methyltetrahydrofolate $(50 \mathrm{nM})$ accumulation against a concentration gradient (6). In this study we also examined the histology of the intestinal tissue after a 5-min incubation of jejunal everted sacs of suckling and adult rats in micellar incubation medium. Staining was performed using periodic-acid Schiff reagents (16). The results showed intact intestinal mucosa, villi and epithelial cells in both cases.

Statistical analysis. Each group of data presented herein is the result of at least three separate experiments from three different rats and is expressed as the mean \pm SEM (pmol/g initial tissue wet weight/unit time). Expressing uptake data in terms of tissue wet weight has been shown by Thomson (17) and Younoszai and Komnick (9) to be suitable for comparison purposes between the different age groups. Data were analyzed using the Student's $t$ test and regression analysis.

\section{RESULTS}

Uptake with time. Uptake of $0.06 \mu \mathrm{M}$ retinol as a function of time was examined in jejunal everted sacs of suckling and adult rats to determine the linearity of the uptake process (Fig. 1). The results showed that retinol uptake is linear for $5 \mathrm{~min}$ of incubation in both suckling and adult rats and occurred at a rate of 31.2 and $6.98 \mathrm{pmol} / \mathrm{g}$ initial tissue wet weight $/ \mathrm{min}$, respectively. At all time points examined, the uptake of retinol in jejunal everted sacs of suckling rats was significantly higher $(p<0.01)$ than that of adult rats. We performed all our subsequent studies at a 5-min incubation period because the uptake of the substrate is linear and appreciable during this time and in order to ensure maximum tissue viability and integrity in vitro.

Transport in ileum versus jejunum. The site of maximum transport of nutrients may change or become confined to specified areas in the intestine with maturation $(7,10)$. We examined the uptake of retinol $(0.06 \mu \mathrm{M})$ in ileal everted sacs of suckling and adult rats and compared the results to that in jejunal everted sacs. The results (Table 1) showed that uptake of retinol in jejunal everted sacs of suckling rats was significantly higher $(p<$ $0.01)$ than that in ileal everted sacs. Similarly, uptake of retinol in jejunal everted sacs of adult rats was significantly higher $(p<$
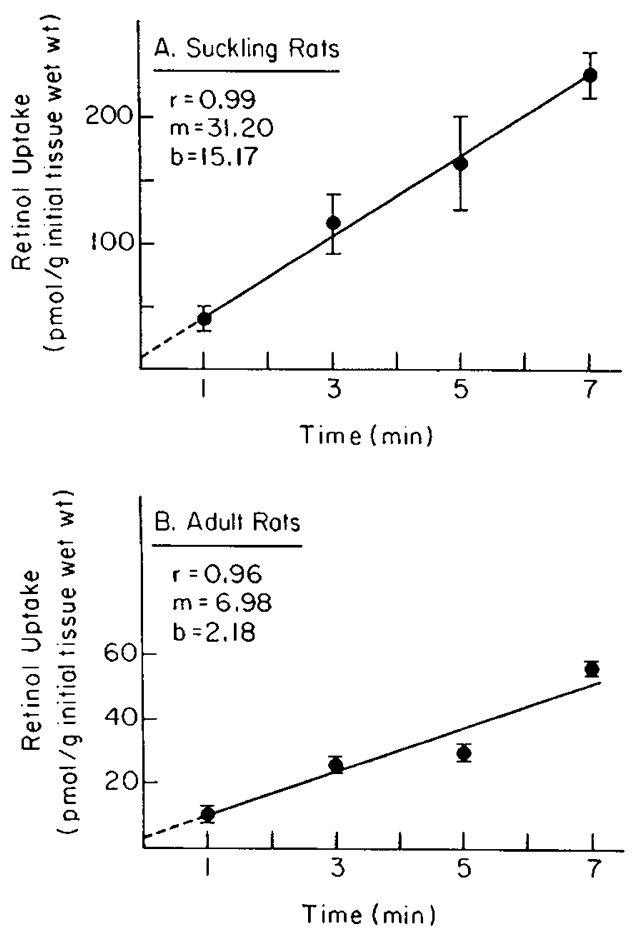

Fig. 1. Transport of retinol in jejunal everted sacs of $(A)$ suckling and $(B)$ adult rats as a function of time. Incubation was performed in a micellar solution of $0.06 \mu \mathrm{M}$ retinol at $37^{\circ} \mathrm{C}$. Each data point represents the mean \pm SEM of at least three separate experiments in three different rats. $Y=m x+b$, where $m=$ slope, and $b=y-$ intercept; $r$ represents correlation coefficient.

Table 1. Transport of retinol in jejunal and ileal everted sacs of suckling and adult rats*

\begin{tabular}{lcc}
\hline & \multicolumn{2}{c}{ Transport (pmol/g initial tissue wet wt/5 min) } \\
\cline { 2 - 3 } & \multicolumn{1}{c}{ Suckling rats } & Adult rats \\
\hline Jejunum & $125.5 \pm 11(6) \dagger$ & $39.9 \pm 4(7)$ \\
Ileum & $44.9 \pm 4.5(6)(p<0.01) \ddagger$ & $20 \pm 2.2(7)(p<0.01)$ \\
\hline
\end{tabular}

* Everted sacs were incubated in a micellar solution of $0.06 \mu \mathrm{M}$ retinol at $37^{\circ} \mathrm{C}$.

$\dagger$ No. of experiments.

$\ddagger$ Comparison was made relative to uptake in the jejunum using the Student's $t$ test.

Table 2. Effect of metabolic inhibitors on transport of retinol in jejunal everted sacs of suckling and adult rats*

Transport (pmol/g initial tissue wet wt/5 $\min$ )

\begin{tabular}{lll}
\cline { 2 - 3 } \multicolumn{1}{c}{ Conditions } & \multicolumn{1}{c}{ Suckling rats } & \multicolumn{1}{c}{ Adult rats } \\
\hline Control & $136 \pm 22(4) \dagger$ & $40.5 \pm 6.1(3)$ \\
2,4-dinitrophenol $(1 \mathrm{mM})$ & $110 \pm 36(4)(\mathrm{NS}) \ddagger$ & $41.1 \pm 2.6(3)(\mathrm{NS})$ \\
Iodoacetate $(1 \mathrm{mM})$ & $136 \pm 10.8(4)(\mathrm{NS})$ & $36.5 \pm 5.9(3)(\mathrm{NS})$ \\
Azide $(10 \mathrm{mM})$ & $140 \pm 20.6(4)(\mathrm{NS})$ & $33.0 \pm 3.3(3)(\mathrm{NS})$ \\
\hline
\end{tabular}

* Jejunal everted sacs were incubated in a micellar solution of 0.06 $\mu \mathrm{M}$ retinol at $37^{\circ} \mathrm{C}$.

$\dagger$ No. of experiments.

¥ Comparison was made relative to control using the Student's $t$ test.

0.01) than that of ileal everted sacs (Table 2). The uptake of retinol in the jejunum and ileum of suckling rats was significantly higher ( $p<0.01$ for both) than that of the corresponding areas of adult rat intestine. 
Uptake as function of concentration. In this study we examined the uptake of retinol in jejunal everted sacs of suckling and adult rats as a function in increasing the substrate concentration $(0.01-$ $15 \mu \mathrm{M})$ in the incubation medium. Saturation of the uptake process of retinol was observed in both suckling and adult rat intestine (Fig. 2). Uptake kinetic parameters (apparent $K_{m}$ and $\mathrm{V}_{\max }$ ) were calculated from the Lineweaver-Burk plot (inset of Fig. 2). Apparent $K_{m}$ of 16.2 and $8.19 \mu \mathrm{M}$ and $V_{\max }$ of 19.78 and $6.24 \mathrm{nmol} / \mathrm{g}$ initial tissue wet weight $/ 5 \mathrm{~min}$ were calculated for suckling and adult rats, respectively.

Effect of metabolic inhibitors and temperature. The effect of the metabolic inhibitors 2,4-dinitrophenol (1 mM), iodoacetate $(1 \mathrm{mM})$, and azide $(10 \mathrm{mM})$ on the uptake of retinol $(0.06 \mu \mathrm{M})$ in jejunal everted sacs of suckling and adult rats was examined in this study. The results were compared to that of simultaneously performed controls. No effect was observed on retinol uptake by any of the metabolic inhibitors tested.
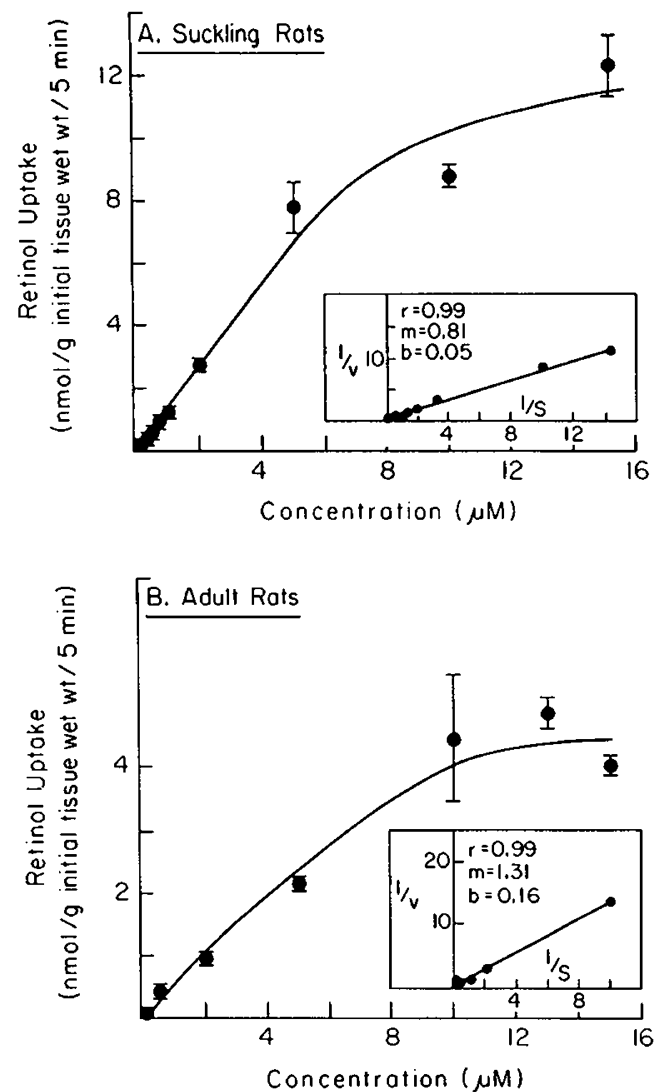

Fig. 2. Transport of retinol in jejunal everted sacs of $(A)$ suckling and $(B)$ adult rats as a function of concentration. Incubation was performed in a micellar solution of different concentrations of retinol $(0.01-15 \mu \mathrm{M})$ for $5 \mathrm{~min}$ at $37^{\circ} \mathrm{C}$. Each data point represents the mean \pm SEM of at least three separate experiments in three different rats. $Y=m x+b$, where $\mathrm{m}=$ slope and $\mathrm{b}=\mathrm{y}$ - intercept; $\mathrm{r}$ represents correlation coefficient. Inset is $1 / \mathrm{S}$ against $1 / \mathrm{v}$.
We also examined the effect of temperature on the uptake of retinol by determining the $\mathrm{Q}_{10}$ value of the uptake process of retinol $(0.06 \mu \mathrm{M})$ in jejunal everted sacs of suckling and adult rats $\left(\mathrm{Q}_{10}\right.$ value is the ratio of uptake at $37^{\circ} \mathrm{C}$ to uptake at $\left.27^{\circ} \mathrm{C}\right)$. $Q_{10}$ values of 2.51 and 1.92 were calculated for retinol uptake in the suckling and adult rat intestine, respectively.

Effect of structural analogues. The effect of the structural analogues retinal $(50 \mu \mathrm{M})$ and retinoic acid $(50 \mu \mathrm{M})$ as well as that of unlabeled retinol $(50 \mu \mathrm{M})$ on the uptake of $0.06 \mu \mathrm{M}\left[{ }^{3} \mathrm{H}\right]$ retinol in jejunal everted sacs of suckling and adult rats was determined. The results (Table 3 ) showed that neither retinal nor retinoic acid had an effect on the uptake of retinol in either age group. However, unlabeled retinol produced significant competition for the uptake of $\left[{ }^{3} \mathrm{H}\right]$ retinol in both suckling and adult rat intestine.

Metabolism of retinol in intestine. We also examined the ability of the intestine of suckling and adult rats to metabolize retinol (see "Material and Methods" for details) (Fig. 3). In tissue extracts of both suckling and adult rat intestine, four peaks of radioactivity were evident corresponding to intact retinol, retinyl linoleate, retinyl palmitate/oleate (not resolved), and retinyl stearate. These compounds accounted for approximately $90 \%$ of the total extractable radioactivity. The distribution between these compounds in the intestinal tissue of suckling rats was $69.9 \%$ as intact retinol, $3.1 \%$ as retinyl linoleate, $20.7 \%$ as retinyl palmitate/oleate, and $6.3 \%$ as retinyl stearate. In the intestinal tissue of adult rats this distribution was similar at 54, 3.9, 29.7 and $7.3 \%$, respectively. In both age groups the radioactivity transported into the serosal compartment which, as mentioned earlier, represents $1-3 \%$ of the total radioactivity taken up by the intestinal everted sacs was found to be entirely in the form of free intact retinol.

\section{DISCUSSION}

Concern over the long-term effects of malnutrition in early life has led to expansion of interest in neonatal intestinal functions and its maturation. Vitamin $\mathrm{A}$ is an essential micronutrient required for normal growth and development processes that are most active in the infancy (suckling) period. No study, however, is available describing vitamin A uptake in the developing intestine of suckling animals and its subsequent maturation in adulthood. This issue was, therefore, investigated in this study. We used retinol as a substrate in our study because vitamin A esters, the form of the vitamin in diets of animal origin and in milk, must be hydrolyzed to free retinol before absorption in the intestine (18). Uptake of retinol in jejunal everted sacs was linear with time for 5 min of incubation in both suckling and adult rats. The uptake of retinol was significantly higher $(p<0.01)$ in the jejunum than the ileum in both suckling and adult rats. This finding indicates that intestinal maturation does not change the preferential site of vitamin A uptake as has been observed for certain other nutrients $(7,10)$. It is of interest to mention here that the enzyme responsible for the reesterification of retinol before incorporation into chylomycrons shows a similar distribution in the intestine in being higher in the jejunum than the ileum (11). Uptake of retinol in the jejunum and the ileum of suckling rats was significantly higher $(p<0.01)$ than that of the

Table 3. Effect of structural analogues on transport of retinol in jejunal everted sacs of suckling and adult rats*

\begin{tabular}{lll}
\hline & \multicolumn{1}{c}{ Transport (pmol/g initial tissue wet wt/5 min) } \\
\cline { 2 - 3 } Analogue & \multicolumn{1}{c}{ Suckling rats } & \multicolumn{1}{c}{ Adult rats } \\
\hline Control & $109 \pm 8.2(4) \dagger$ & $29.3 \pm 1(3)$ \\
Retinal $(50 \mu \mathrm{M})$ & $91 \pm 8(4)(\mathrm{NS}) \ddagger$ & $29.6 \pm 0.5(3)(\mathrm{NS})$ \\
Retinoic acid $(50 \mu \mathrm{M})$ & $92 \pm 8.5(4)(\mathrm{NS})$ & $33.4 \pm 2(3)(\mathrm{NS})$ \\
Retinol $(50 \mu \mathrm{M})$ & $33 \pm 5.4(4)(p<0.01)$ & $10.97 \pm 0.65(3)(p<0.01)$ \\
\hline
\end{tabular}

\footnotetext{
* Jejunal everted sacs were incubated in a micellar solution of $0.06 \mu \mathrm{M}$ retinol at $37^{\circ} \mathrm{C}$.

$\uparrow$ No. of experiments.

$\ddagger$ Comparison was made relative to control using the Student's $t$ test.
} 

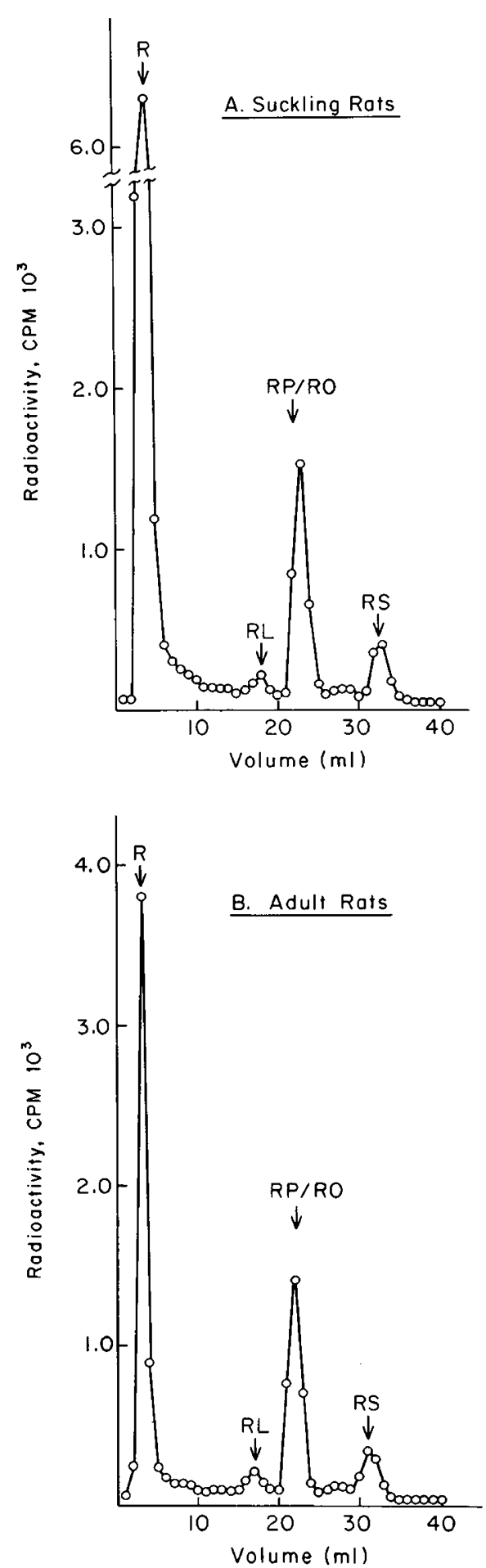

Fig. 3. Metabolism of retinol in jejunal tissue of $(A)$ suckling and $(B)$ adult rats. Jejunal everted sacs were incubated in a micellar solution of $0.06 \mu \mathrm{M}\left[{ }^{3} \mathrm{H}\right.$ ]retinol for $5 \mathrm{~min}$ at $37^{\circ} \mathrm{C}$. Organic extracts of jejunal tissue were taken to dryness under stream of $\mathrm{N}_{2}$, dissolved in chloroform/ methanol, and injected for analysis by HPLC. Fractions of $1.0 \mathrm{ml}$ were collected, taken to dryness, and radioactivity determined. The elution positions of authentic retinol $(R)$, retinyl linoleate $(R L)$, retinyl palmitate $(R P)$, retinyl oleate $(R O)$, and retinyl stearate $(R S)$ are indicated.

corresponding segments of adult rat intestine. This observation clearly demonstrates how the intestine of the rapidly growing animal meets the high demand for the vitamin to maintain normal growth and development.
Uptake of retinol as a function of concentration was saturable in both suckling and adult rat intestine. The kinetic parameters of the uptake process, however, were different in the two age groups. The apparent $K_{m}$ of the uptake process decreased from suckling to adulthood, indicating an improvement (i.e. an increase) in the affinity of the uptake system with maturation. However, $V_{\max }$ of the uptake process decreased from suckling to adulthood indicating that the number and/or the activity of the uptake carrier decreases with maturation. The factors responsible for these changes are not known but may include hormonal changes (19), physicochemical changes in the composition and fluidity of the enterocyte membrane $(20,21)$, and/or changes in the thickness and resistance of the unstirred water layer (the unstirred water layer modulates absorption of substrates, especially lipid-soluble nutrients) (22).

The effect of the structural analogues, retinal and retinoic acid, on the uptake of $\left[{ }^{3} \mathrm{H}\right]$ retinol was also examined in this study. Neither compound appeared to have an effect on retinol uptake in either suckling or adult rat intestine. This observation indicates that a free hydroxyl group at the end of the hydrocarbon chain of the vitamin A molecule is essential for the recognition and interaction of the substrate with the uptake system. This conclusion is consistent with the previous observation that vitamin A esters cannot be transported without prior hydrolysis to free retinol (18). Further studies with other analogues of the vitamin are required to delineate the details of the structure/activity relationship between the retinol molecule and its uptake system in the intestine.

The uptake process of retinol both in suckling and adult rats appeared to be energy independent. This conclusion is based on the observation that a variety of metabolic inhibitors added to the mucosal medium caused no effect on retinol uptake. These findings confirm the previously reported observation of Hollander and Muralidhara (2) in adult rats but is in contrast with the reported observation of El-Gorab et al. (1) who reported considerable inhibition of retinol uptake by a metabolic inhibitor. Retinol transport appeared to be partially dependent on temperature with a $Q_{10}$ value of 2.51 and 1.92 for retinol uptake in suckling and adult rats, respectively. The saturation in retinol uptake as a function of concentration, combined with the inhibition by the unlabeled substrate, the lack of requirement for energy, and the partial temperature dependence, classifies the uptake process in both the suckling and adult rat intestine as a passive, carrier-mediated phenomenon.

Metabolism of the transported (into the tissue) retinol by the intestinal tissue was similar in the suckling and adult rats indicating the maturity of the metabolizing system during the suckling period. In the intact animal internalized retinol is esterified within the absorptive cell with long-chain fatty acids before incorporation into chylomicrons for transport via the lymph. The ester pattern produced is quite consistent and relatively independent of diet (23). The predominate fatty acids found in the retinyl esters are palmitate, stearate, oleate, and linoleate. The HPLC system we used here would not resolve retinyl palmitate and oleate but the pattern and relative proportion of esters observed is essentially identical to that reported for intact animals. The relative proportion of palmitate/oleate, stearate, and linoleate averaged from two separate studies with intact animals $(23,24)$ as reported by Ong et al. (11) is 68:23:8. Here we observed the relative proportion of $69: 21: 10$ and 73:18:10 for suckling and adult rats, respectively. This indicates that the retinol internalized by the everted sac was metabolized in the same manner as in the intact animal and suggests that we have duplicated the normal uptake process.

Ong (25) has recently described a cytoplasmic protein in the epithelial cells of the small intestine which binds retinol with high affinity $\left(\mathrm{kDa}=3 \times 10^{-8} \mathrm{M}\right)$. This protein has been named CRBP II. Because CRBP II was found solely in the absorptive epithelial cells of the villi, it was suggested that this protein may be involved in the overall intestinal handling of retinol (25). Our 
present findings are consistent with this suggestion: 1) uptake of retinol was higher in the jejunum than the ileum of both suckling and adult rats, an observation that corresponds with the higher CRBP II content of jejunal epithelial cells as compared to that of the ileum (25), and 2) uptake of retinol was higher in the intestine of suckling rats as compared to that of adult rats, an observation that again corresponds with the higher content of CRBP II in the intestine of suckling rats as compared to that of adult rats (25). It has been suggested by Hollander and Muralidhara (2) that retinol, because of its lipid nature, may penetrate the brush border membrane of the absorptive cells by passive diffusion followed by transfer of the compound to a carrier protein. According to this hypothesis the saturation as a function of concentration observed in their transport study and in our uptake studies is the result of interaction of retinol with the cytoplasmic carrier protein. Assuming that this cytoplasmic protein is CRBP II, our findings in this study argue against the above concept. CRBP II binds with high affinity not only to retinol but also to retinal $\left(\mathrm{kDa} 5 \times 10^{-8} \mathrm{M}\right)$ (i.e. retinal competes with retinol for binding to CRBP II) (26) but retinal did not affect the uptake of retinol in jejunal everted sacs of suckling and adult rats. Thus, our findings most probably reflect the existence of a membrane-associated uptake carrier for retinol. The previous finding of Mahaderan et al. (18) that vitamin A esters cannot be absorbed unless hydrolyzed to free retinol further support this suggestion. Similarly, the transport of the lipid-soluble fatty acids across the brush border membrane was thought previously to be by simple diffusion (27). However, recent studies have clearly indicated the existence of a membrane-associated carrier system (28).

In summary, our study shows that the uptake of retinol is higher in the intestine of suckling rats as compared to that of adult rats and in both cases the uptake occurs by a passive, carrier-mediated process. Furthermore, changes in the activity and/or number and affinity of the uptake system occur with maturation.

\section{REFERENCES}

1. EL-Gorab M, Underwood BA, Loerch JD 1975 The roles of bile salts in the uptake of $\beta$-carotene and retinol by rat everted gut sacs. Biochim Biophys Acta 401:265-277

2. Hollander D, Muralidhara KS 1977 Vitamin A intestinal absorption in vivo: influence of luminal factors on transport. Am J Physiol 232:E471-E477

3. Hennings SJ 1987 Functional development of the gastrointestinal tract. In: Physiology of the Gastrointestinal Tract, Johnson LR, (ed). Raven Press, New York, pp 282-300

4. Barnard J, Ghishan FK, Wilson FA 1985 Ontogenesis of taurocholate transport by ileal brush border membrane vesicles. J Clin Invest 75:869-873

5. Ghishan FK, Jenkins JT, Younoszai MK 1980 Maturation of calcium transport in the rat small and large intestine. J Nutr 110:1622-1628
6. Said HM, Ghishan FK, Murrell JE 1981 Ontogenesis of intestinal transperir of 5-methyltetrahydrofolate in the rat. Am J Physiol 249:G567-G571

7. Said HM, Redah R 1988 Ontogenesis of intestinal transport of biotin in the rat. Gastroenterology 94:68-72

8. Said HM, Greene HL, Moore MC, Ghishan FK 1987 Developmental maturation of D-glucose active transport system in rat intestine. Digestion 36:195200

9. Younoszai MK, Komnick K 1982 Maturation of the small intestine: Absorption of L-valine in rats. Pediatr Res 16:756-760

10. Bamford DR, Ingham PA 1975 Sugar absorption by fetal and neonatal rat intestine in vitro. J Physiol (Lond) 248:235-248

11. Ong DE, Kakkad B, MacDonald PN 1982 Acyl-CoA-independent esterification of retinol bound to cellular retinol-binding protein (type II) by microsomes from rat small intestine. $J$ Biol Chem 262:2729-2736

12. Wilson TH, Wiseman G 1954 The use of everted sacs of small intestine for the study of the transfer of substances from the mucosal to the serosal surface. J Physiol (Lond) 123:116-125

13. Lherminier M, Alvarado F 1981 Virtual elimination of the interference of unstirred water layers on intestinal sugar transport kinetics by use of the tissue accumulation method at appropriate shaking rates. Pflugers Arch 380:155-158

14. Kobayashyi Y, Mandsley DV 1980 Practical aspects of double isotope counting In: Liquid Scintillation Counting, Bransome E, and Grune S (eds). Grune and Stratton Inc., New York pp 76-85

15. Zachman RD, Kakkad B, and Chytil F 1984 Perinatal rat lung retinol (vitamin A) and retinyl palmitate. Pediatr Res 18:1297-1299

16. McManus JFA 1946 Histological demonstration of mucin after periodic acid. Nature 158:202

17. Thomson ABR 1979 Unstirred water layer and age-dependent changes in rabbit jejunal D-glucose transport. Am J Physiol 236:E685-E691

18. Mahadevan S, Sastry PS and Ganguly J (1963). Studies on metabolism of vitamin A. Biochem J 88:534-539

19. Forstner G, Garland G 1976 The influence of hydrocortisone on the synthesis and turnover of microvillous membrane glycoproteins in suckling rat intestine. Can J Biochem 54:224-230

20. Schwarz SM, Hostetler B, Ling S, Mone M, Watkins JB 1985 Intestina membrane lipid composition and fluidity during development in the rat. Am J Physiol 248:G200-G207

21. Schwarz SM, Ling S, Hostetler B, Draper JP, Watkins JB 1984 Lipid composition and membrane fluidity in the small intestine of the developing rabbit. Gastroenterology 86:1544-1551

22. Westergaard H, Dietschy JM 1974 Delineation of the dimensions and permaebility characteristics of the two major diffusion barriers to passive mucosal uptake in the rabbit intestine. $\mathrm{J}$ Clin Invest 54:718-732

23. Huang HS, and Goodman DS 1965 Vitamin A and carotenoids: intestina absorption and metabolism of ${ }^{14} \mathrm{C}$-labelled vitamin $\mathrm{A}$ alcohol and $\beta$-carotene in the rat. J Biol Chem 240:2839-2844

24. Ross AC 1981 Separation of long-chain fatty acid esters of retinol by highperformance liquid chromatography. Anal Biochem 115:324-330

25. Ong DE 1984 A novel retinol-binding protein from rat. J Biol Chem 259:14761482

26. MacDonlad PW, Ong DE 1987 Binding specificities of cellular retinol-binding protein and cellular retinol-binding protein, type II. J Biol Chem 262:1055010556

27. Simmonds WJ 1976 Uptake of fatty acids and monoglyceride. In: Lipid Absorption: Biochemical and Clinical Aspects, Rommel K, Goebell H, Bohmer R (eds). MTP Press, Lancaster, England, pp 51-56

28. Stremmel W, Lotz G, Strohmeyer G, Berk PD 1985 Identification, isolation and partial characterization of fatty acid binding protein from rat jejunal microvillous membranes. J Clin Invest 75:1068-1076 